\title{
FOREWORD
}

It is rare for a major scientific hypothesis to remain untested for many years, particularly if it is questioned and requestioned. It may be unprecedented for an essentially correct hypothesis to be the center of a raging controversy for more than a hundred years. Yet that is the history of Darwin's hypothesis of the origin of coral atolls through subsidence, which he documented for the first time in this book when it was published in 1842.

Since that time many famous scientists have expressed doubt about the general or specific application of Darwin's hypothesis. Emphasis has been placed on the importance of flat antecedent banks as platforms for atolls, and on the effects of Pleistocene changes in sea level produced by the formation of continental glaciers. A careful reading of this book will disclose that these or similar possibilities were considered by Darwin but relegated to minor roles in the formation of atolls.

The changes in sea level he attributed to vague "astronomical causes" rather than to the wax and wane of glaciers, but the general effects-other than cooling-would be the same. It is now certain, however, that sea level was lowered, perhaps four hundred feet, within the last few hundred thousand years, and may have been higher within the last few thousand years. Had this information been available to Darwin, he undoubtedly would have changed some of the emphasis in his argument. Indeed, in all his geological researches based on the voyage of the Beagle, Darwin suffered for lack of these crucial facts. How often one sees his towering inspiration and thinks that, if only he had known of Pleistocene changes in sea level, his explanations would be exactly right.

One cannot be sure, however, with regard to the origin of atolls. Possession of the facts of sea-level change caused geologists to be obsessed with the origin of the superficial form of atolls. Darwin's 
arguments for subsidence based on grouping and distribution of different types of reefs were deëmphasized or ignored. These arguments form the crux of this book. At times, Darwin seems to be concerned with the origin of coral reefs only so far as it gives evidence for regional subsidence of the sea floor.

The hypothesis of subsidence was tested by the Royal Society in 1896, when a hole was drilled on Funifuti Atoll in the Ellis group of the Pacific. Unfortunately the results were inconclusive. It was not until a decade ago that instruments became available which were capable of testing the hypothesis of subsidence. The evidence collected is from four sources: samples obtained with modern oilwell-drilling equipment, samples dredged by oceanographic ships, continuously recorded echo soundings of water depth, and shipborne seismic soundings of crustal thickness.

Three atolls and one coral island have been drilled in the Pacific Basin. On one atoll, Eniwetok, the whole coral capping has been penetrated and the volcanic platform sampled. All the drilling has demonstrated that subsidence has predominated for tens of millions of years (fig. 1), although intermittent, moderate uplift has not been uncommon.

The costly and time-consuming drilling has been supplemented by determination of the thickness of coral in atolls by seismic techniques. The actual measurements give only the thickness of layers with certain physical properties, but the distinctive properties of coral and basalt usually make them easy to identify. Seismic studies of four atolls show that each has a capping of coral several thousand feet thick.

Assuming that all other atolls have the same structure as those that have been drilled or studied seismically, Darwin's hypothesis of widespread subsidence can be taken as proved. Even the necessity for this assumption, however, has been eliminated by oceanographic sounding and dredging. Sprinkled among the atolls of the western Pacific are about a hundred and fifty "guyots" or ancient islands now submerged to depths as great as a mile (fig. 2). They were originally identified as former islands solely because they are truncated volcanic cones and the truncation could be ascribed only to erosion at sea level. This deduction has been amply confirmed by 


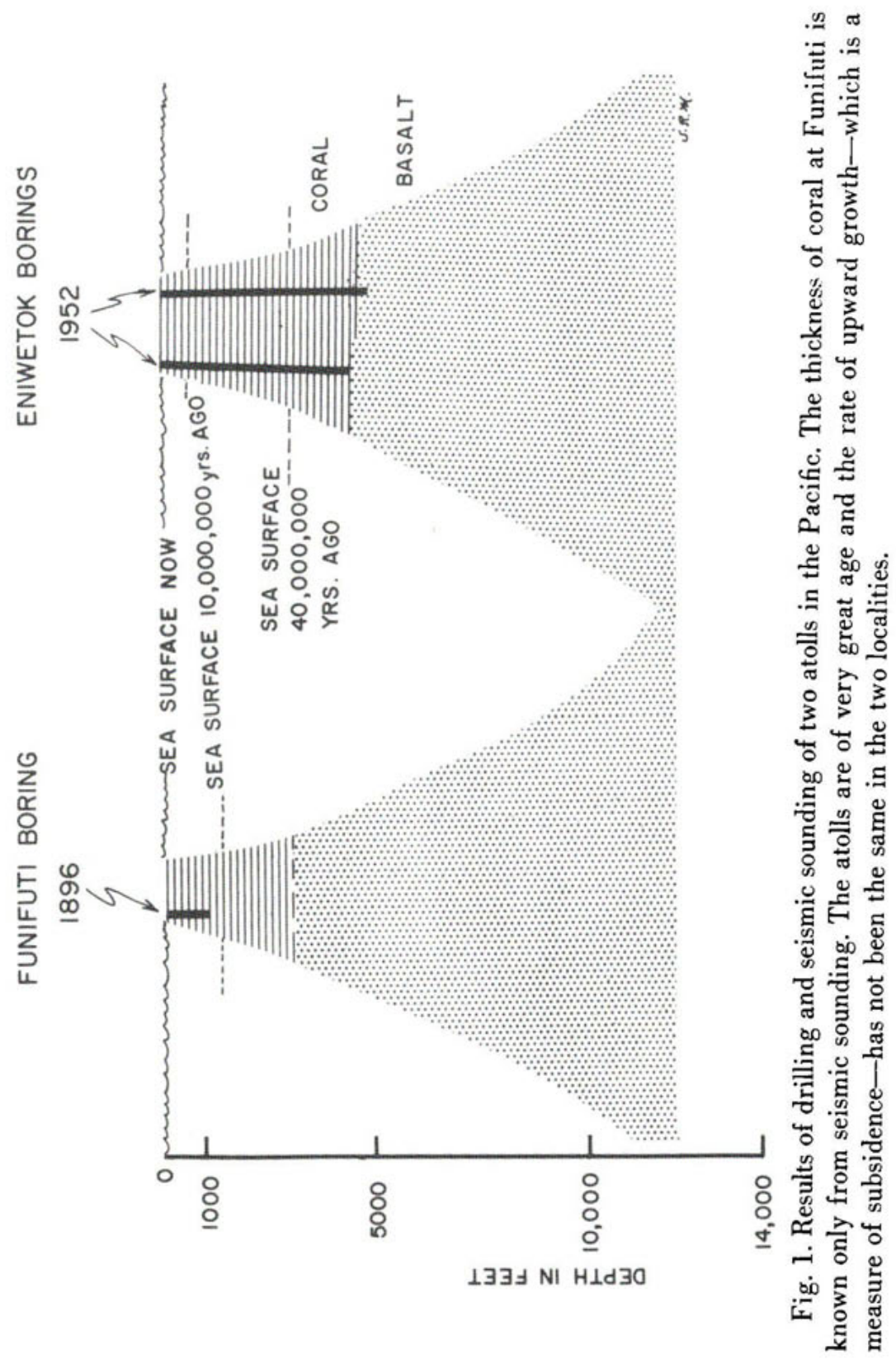




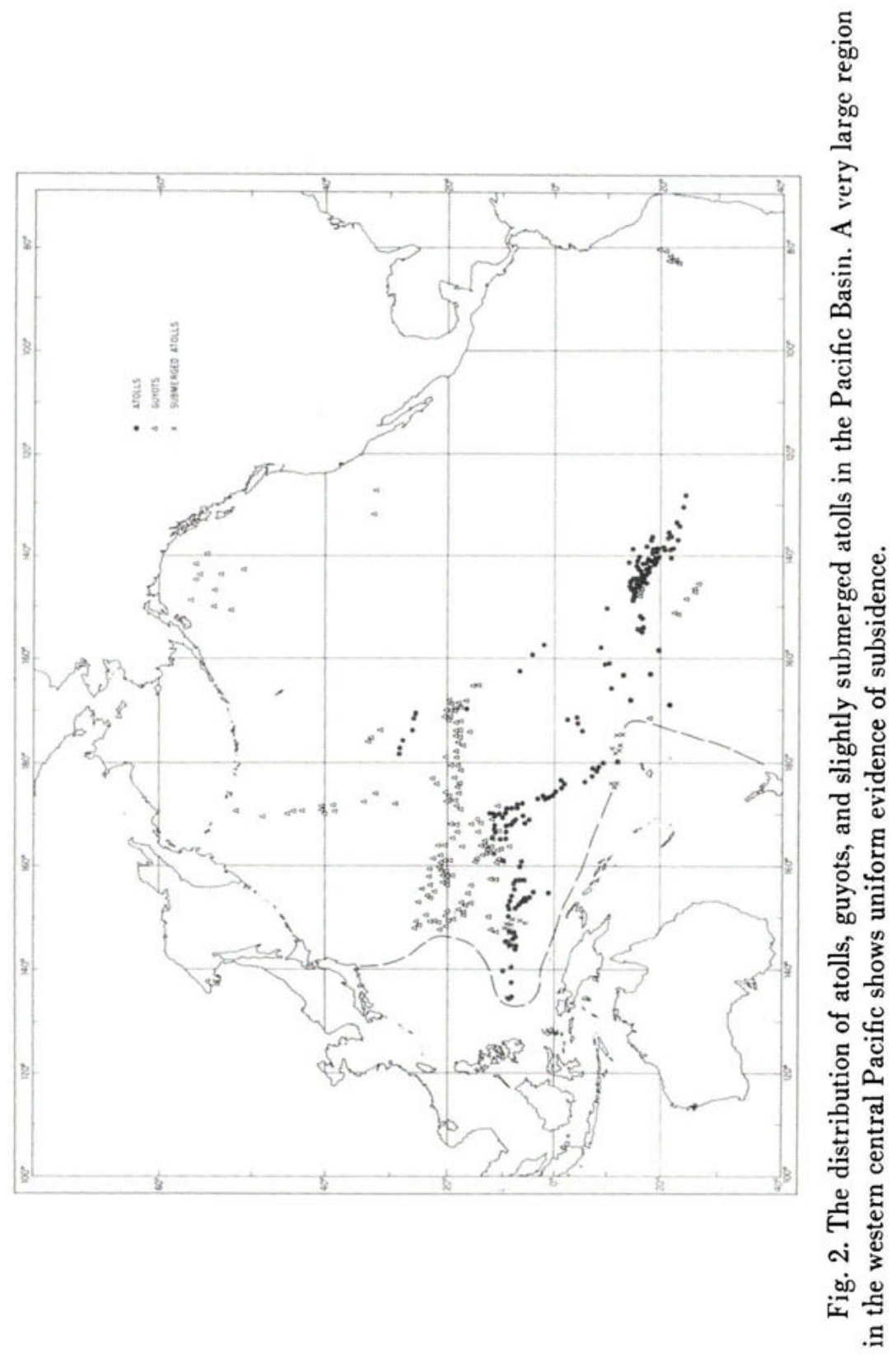


deep-sea dredging of guyots. The tops are covered with rounded cobbles and fossils typical of very shallow water.

A complete sequence of development of submarine volcanoes is now known. Thousands of small volcanoes never reach the surface, but during the last hundred million years several hundred volcanoes have grown large enough to become islands in the Pacific Basin. They have then been attacked by stream and wave and, in what is assumed to be only a few million years, they have been leveled to shallow banks. With minor interruptions, they have since subsided steadily. Former islands in favorable locations have been capped by coral that has grown upward as fast as they subsided, and these are atolls. Other former islands, lacking the coral, are now guyots.

It is evident that Darwin's hypothesis of the association of atolls with regional subsidence is no longer open to dispute. The cause of the subsidence is the hotly debated question of the day.

H. W. Menard

\section{La Jolla}

July, 1961 
